\title{
An Instructional Design Model Based On the Problem-Based Learning
}

\author{
Corina Musuroi ${ }^{1}$, Ioana Iacob $^{1}$ \\ "Tibiscus" University of Timisoara
}

\begin{abstract}
This paper aims to describe a project of instructional design conceived to promote the principle of student-centered education. This pattern of education targets the students' knowledge needs by continuously modeling their learning environment.

The described model is actually a challenge, a path towards the type of knowledge based on the psychoemotional stress caused by situations and circumstances which are present in the social and economic activity and cannot find an immediate solution in the references recommended by the curricula.
\end{abstract}

Keywords: university, economical institutions, situational circle, problem-based learning.

\section{Introduction}

The knowledge gained during the years of study aims to build the skills necessary to conduct specialized activities and to identify solutions when there are impediments to their realization.

According to the requirements of the national education system, the completion of a study program - bachelor, master or doctoral studies - provide a qualification clearly defined through individual skills, knowledge and abilities, acquired by attending the university curricula. The highest the level of study is the more complex the acquired competences are.
Therefore the third cycle of doctoral studies builds innovative independence in solving problems by creating solutions to situations.

\section{A situational circle and learning environment}

What is in fact a problem at the workplace? It is a challenge, a psychoemotional stress determining the individual to search for a solution in order to regain the interior balance. The mechanism of reaction can be described using the situational circle, a model developed by Thure von Uexküll. What is the situational circle? It is an interaction of two articulated hemispheres, one of the sense world and the other of the effect world. Considering Uexküll's model, it can be stated that in the learning environment, the situational circle would be the systematic reunion between the emotion of the knowledge process and the behavior as a manifestation determined by this emotion.

The two dimensions of the observation and action (sense and effect) are prestructured by the human being's anatomic and functional organization, which allows the functional circle to be closed, with no fractures between the two completely different worlds. Thus, the problematic environmental situation, the problem to be solved, is notified by the individual through the sense organs and then integrated at the cortical level. By processing the received information, the individual creates a problem-solving strategy that 
turns into a behavior which leads successfully to the exit stage, to extinguishing the problem and to solving the circle.

The integration and data processing means assigning meanings, which is strongly determined by one's learning history from the own experience or by gaining knowledge from others' experience. At the high level of the professional training, the assignment is completed with the development of meanings so that the problem solving process should be a creative-innovative one and not an adaptation of a previous personal or assimilated experience to the current problematic context.

Therefore, the way in which a person solves a problem by closing the functional circle in order to reach the state of equilibrium depends on his ability to assign meanings and afterward to work with them.

\section{Description of the instructional design}

Planning the instructional design of the study program must create the learning environment suitable for assigning meanings and for challenging the mobility of their combination and processing in order to generate new, creative meanings. Thus, the student can learn by using the theoretical knowledge that he has acquired by himself or provided by other people so that he might become able to develop judgments and reasoning. The more complex and diverse the potential non-formal or informal knowledge sources are the more structured the learning process is.

These sources can be made available to students through the creation of study groups implying employees of the socioeconomic institutions whose field of activity is reflected in the content of the study program [1].
In this context, the planning of the instructional design involves [2]:

- Creating a learning network in which the socio-economic institutions represent the nodes. The center of the network is the university, the institution providing education services.

- Designing the educational process

- Applying optimum learning techniques to serve the goal.

- Selecting learning technologies, considering that the classic style of the teaching in the classroom is not fully applicable.

\subsection{Creating a learning network}

Creating such a network requires the collaboration between the university, as an education and research provider, and the socio-economic units within a stable functional structure that meets all the partners' interests.

For the university, the network would successfully meet the requirements involved by the student-centered education principles:

a. The modification of the classical learning model by replacing the procedure of providing and storing information with the process of critical and creative thinking, of simulation and problem solving. It can be noted that this involves a tendency to developing high professional skills, critical and constructive reflection, creativity and innovation starting with the first level of the university instruction, the bachelor studies.

b. Creating learning experiences in different formal, informal and non-formal learning contexts. Variability depends on the connection level between the network partners. Its quality depends on the degree in which the communication and the meeting of the needs are expressed [3, 4].

In terms of socio-economic units, the functioning in such symbiosis would provide expertise and permanent qualifica- 
tion to their employees. The group learning to which teachers, students and staff participate, enables knowledge transfer from the university to the socio-economic environment so that it would create a phenomenon of permanent professional development without costs on the part of the employer.

Moreover, solving the problems identified in the company through the participation of university specialists would ensure the maintenance and application of the university research outcomes in the current activity of the socio-economic institutions

\subsection{Designing the educational process}

This approach will establish rigorously:

- The objectives of the training program, the material in the curriculum, expressed as knowledge, skills, and acquired competences;

- The curriculum map classically described by the themes and topics of the course and its projects.

- The training contexts necessary for studying the curriculum content, considering the necessity of involving the staff from the socio-economic environment in the training process. This will represent the provider of problems to be solved and will offer the material basis necessary for the learning process.

The advantages of such a design are that it provides authenticity and relevance for the educational process. The student will be motivated to study as he/she observes that the effort of learning has immediate applicability in the real world, in solving the problems posed by the environment in which he/she will integrate after graduation. Thus, by motivating the students, the communication between the participants to the created learning network is strengthened.

\subsection{Learning techniques compatible with the proposed model}

The model uses the "Problem-based learning" principle - a teaching method in which learning is achieved by placing the individuals of the study group in the situational circle. The problems are introduced by the employees from the socioeconomic institutions of the network. They bring into question real problems taken from the current activity of the institution.

Such problems are real, competitive, and need a solution to be applied in a context. The debate can lead to presenting different viewpoints, to identifying constraints and conditions required for a solution. Learning is stimulated by the teacher who will ask key questions and guide the discussions leading to the knowledge transfer between the two partner parties of the group - students and staff.

In this way, students can identify what they know, what they do not know and what they need to know to solve the problem. They can discover how to access the information needed to find the solution and where it can be found. The answers to these questions are not provided exclusively by the teacher. They can come from any member of the working group, in so far as he/she has the previous experience from which to identify the elements answering the question.

\subsection{Establishing learning technologies}

In determining the learning technologies the teacher needs to bear in mind that he collaborates with a working group of students and people from socio-economic institutions. As a result, the organization of the teaching process depends on the participants' schedule, the distance between the institutions, and the possibility of movement. 
In order to meet the organizational needs, this sort of instructional design requires blended learning techniques $[5,6]$, within which some types of learning tools can be mixed: face-to-face learning, online- learning and mobile learning.

Face-to-face learning is the classical method by which learning occurs through the interaction in the classroom which assumes the presence of all group members in the same space to participate in the activity.

The on-line learning may include synchronous chat, web based teleconferencing (audio graphics), or similar technology [7]. The advantage of this method is the fact that individuals do not depend on each other regarding the presence in the same space. The socio-economic institutions can be placed far away so that moving to a certain location at certain time can be an impediment to accomplishing the course. But the method requires that the group members should be provided with audio-video equipment, plug-ins and other media.

For the mobile-learning type it is necessary that each member of the learning network should have a compact portable digital device, employed in communication through wireless and mobile phone networks such as I-Pod or Smartphone. The method is advantageous because it allows contacting people who are not part of the learning group during the class, people who can provide answers due to their qualification and experience. It is like benefiting from a living, human library, achieved through technology [8].

Organizing and managing a technologyassisted class requires that the teacher should have management skills to administer the interaction between the group members. He must have the knowledge of a specialist in technology to "identify, select and use the most appropriate technology tools for all learning activities" (ETS, 2003).

\section{Discussion}

In the current context of reforming the education systems, the guiding principle is to achieve a partnership between higher education institutions and the units of the socio-economic environment in order to facilitate communication and expertise transfer between the two environments education and production.

The model presented describes the way learning within the network functions. In its center there is the university, while the socio-economic institutions on the labor market represent its nodes. The instructional program is presented as a system in which, depending on the course topic, the university appeals to these institutions in order to create a work group: the class participating in a particular learning activity, depending on the activity profile.

Therefore, this group changes from one course to the other, according to the topic, to the sources of knowledge and expertise, to the need for communication with the productive environment [10]. Thus the students are provided with a new learning context where he/she is asked to solve problems, being transferred to a situation circle in which finding a solution represents the only exit. This method places the student in the center of activity; it creates learning emotions and a working environment that enables the exchange of ideas in a mental space that is dynamic, mobile and interactive.

The participation in learning activities can be done face-to-face through the attendance of members in the classroom or it can be virtual by using modern technologies such as e-learning and mobile learning. These offer independence to the group members, especially to those engaged in socio-economic units who will be exempted from moving to a certain place at a certain time. Moreover, by using $\mathrm{M}$ learning it becomes possible to present learning experiences directly 
from the laboratories or the production environments of these institutions.

The benefits of such a construction concern the people involved, students or employees, and the two institutions to which they belong.

Network communication strengthens the link between the educational and research institute and the units from the socio-economic environment, reducing the phenomenon of rupture and isolation between the two environments. The university adapts its curricula to the needs of the labor market; it trains specialists as required and facilitates the continuous professional development at the workplace for the employees of the institutions.

The institutions from the economic environment turn into a practical working environment, where the acquired knowledge can be implemented or new information can be learnt in an informal environment. The communication between the academic and socio-economic environments is therefore strengthened, the sense of direction being from the professional environment to the educational research one.

\section{References}

[1] M. Tutunea, R.V. Rus, V. Toader, "Traditional Education vs. E-learning in the vision of Romanian business students", in NAUN International Journal of Education and Information Technologies, Issue 1, Volume 3, 2009, pp 46-55

[2] L. Stanca, I. Pop, C. Felea, G. Chiş, H. GreY. Inoue, Cases on Online and Blended ing Technologies in Higher Education: Concepts and Practices, Information science reference, New York, 2010

[3] Singh. Harvey, Building Effective Blended Learning Programs, Educational Technology, Volume 43,
Number 6, November - December 2003

[4] E. Stacey, P. Gerbic, "Effective Blended Learning Practices: Evidence-Based Perspectives" in ICT Facilitated Education, Information science reference, New York, 2009 , pp. $2-4$

[5] J. F. Troha, "Bulletproof Instructional Design. A Model for Blended Learning", USLA Journal, vol. 16, nr.5, May 2002;

[6] H. Singh, "Building Effective Blended Learning Programs", in Educational Technology, Volume 43, Number 6, November - December 2003 pp 2-4,

[7] C. Whitmyer, G. T. Grimes, "Comparative features analysis of leading collaboration software", Published by FutureU ${ }^{\mathrm{TM}}$ (www.futureu.com) San Francisco, California, 2003;

[8] C. Whitmyer, "Instructional Design for Online Learning", Published by FutureU Press The University of the Future, LLC (aka FutureUTM), 1999; pp 3-9

[9] K. Uenosono, S. Kaneko, T. Tachibana, A. Sato, M. Hashidate, A. S. Komiya, "CAI System to Identify Each Weak Part of a Student: A New Proposal of a Student Model and an Instruction Program", International Journal of Education and Information Technologies, Issue 1, vol. 3 , 2009;

[10] I. Šimonová, P. Poulová, "Electronic education in the Czech Republic in 2003-10: development and students attitudes, NAUN International Journal of Education and Information Technologies, Issue 4, Volume 4, 2010, pp 214-223. 